\title{
A filosofia moral e política de Hobbes em duas tradições interpretativas do Leviatã
}

\author{
Hobbes moral and political philosophy in two \\ interpretative traditions of Leviathan
}

Jairo Rivaldo Silva ${ }^{1}$

\begin{abstract}
1 Mestre em Filosofia pela UFPE. Especialista em Ciência Política pela Universidade Cândido Mendes. Professor de Filosofia Geral e Filosofia Jurídica no Centro Universitário Maurício de Nassau em Caruaru-PE, Brasil.

E-mail: jairorivaldo@gmail.com Orcid: $\underline{\text { http://orcid.org/0000-0002-0598-7583 }}$
\end{abstract}

RESUMO: O objetivo do presente artigo é apresentar e confrontar os pressupostos de duas tradições interpretativas Leviatã de Thomas Hobbes. Pretendo demonstrar como, a partir dos pressupostos e dos critérios de interpretação de cada uma delas, teremos não apenas duas abordagens diversas, mas resultados e soluções distintas para problemas políticos e morais que o próprio Hobbes buscou solucionar com essa obra. Na primeira parte do artigo, apresentarei os aspectos inovadores da nova interpretação do Leviatã em contraposição às interpretações tradicionais ou ortodoxas. Na segunda parte, confrontarei essa abordagem com a abordagem tradicional sobre um problema específico, mas central na filosofia de Hobbes: o problema da desordem social. Apresentarei a tese tradicional segundo a qual a solução para o problema da desordem seria criar um poder capaz de impor sanções que não permitissem que o interesse racional egoísta atuasse de forma irrestrita. Em seguida, apresentarei a solução revisionista segundo a qual a solução seria produzir uma estável e apropriada reconfiguração dos diversos interesses morais e religiosos dos cidadãos através de um processo de educação contínua responsável pelo consenso social.

Palavras-chave: Interpretação. Leviatã. Filosofia moral e política.

ABSTRACT: The aim of this paper is to present and confront the presuppositions of two interpretative traditions Leviathan by Thomas Hobbes. I intend to demonstrate how, from the presuppositions and interpretation criteria of each one, we will have not only two different approaches, but distinct results and solutions to the political and moral problems that Hobbes himself sought to solve with this work. In the first part of the article, I will present the innovative aspects of Leviathan's new interpretation as opposed to traditional or orthodox interpretations. In the second part, I will confront this approach with the traditional approach to a specific but central problem in Hobbes's philosophy: the problem of social disorder. I will present the traditional thesis that the solution to the problem of disorder would be to create a power capable of imposing sanctions that would not allow the selfish rational interest to act unrestrictedly. Next, I will present the revisionist solution whereby the solution would be to produce a stable and appropriate reconfiguration of the diverse moral and religious interests of citizens through a process of continuing education responsible for social consensus.

Keywords: Interpretation. Leviathan. Moral and political philosophy.

\section{Introdução}

Em linhas gerais, a abordagem tradicional sobre o Leviatã e sobre a filosofia de Hobbes defende uma interpretação baseada nas seguintes características: 1) o autor era alguém que descreve o ser humano como 
um ser cujo único interesse racional é o auto interesse (GAUTHIER, 1969: 5); 2) as ações morais estão baseadas estritamente em razões prudenciais (PETERS, 1956: 173); 3) a religião não desempenha um papel importante em sua teoria moral e política (RALWS, 2012: 29).

Em grande medida, as interpretações tradicionais dependem de uma obra sobre o Leviatã surgida em 1969 escrita por David Gauthier, The Logic of Leviathan: the moral and political theory of Thomas Hobbes. A partir da década de 1990, surgiu uma série de interpretações alternativas para contestar, em grande medida, os pressupostos da interpretação tradicional. Entre essas obras, destaco as obras de Sharon Lloyd (1992) e de Bernard Gert (2001) a partir das quais uma tradição alternativa à abordagem ortodoxa surgiu. Essa tradição passou a ser conhecida como interpretação revisionista do Leviatã. De modo geral, essa abordagem se baseia nos seguintes pressupostos: 1) Hobbes era um teísta (embora, não um teísta convencional); 2) os seres humanos não são motivados exclusivamente pelo egoísmo psicológico, mas existem outros interesses que motivam os seres humanos a agir na sociedade; 3) a obrigação moral não está baseada estritamente na prudência, nem tão pouco exclusivamente na religião, mas numa convergência de razões: razões morais, razões prudenciais e razões religiosas; 4) a parte religiosa do Leviatã não pode ser descartada, mas tem o seu lugar na teoria e no argumento de Hobbes para solucionar o principal problema do Leviatã: o problema da desordem social.

Esse artigo tem o objetivo de mapear e confrontar os pressupostos dessas duas tradições interpretativas recentes do Leviatã. Não se trata de tentar refutar nenhuma das abordagens aqui apresentadas, mas sim de demonstrar como, a partir dos pressupostos e dos critérios de interpretação de cada uma delas, teremos não apenas duas abordagens diversas, mas resultados e soluções distintas para problemas políticos e morais que o próprio Hobbes buscou solucionar no Leviatã.

Assim, pretendo reconstruir alguns aspectos revisionistas da interpretação do Leviatã a partir da obra recente de Sharon Lloyd. Em linhas gerais, os aspectos da teoria moral e política de Hobbes que sofreram revisões na interpretação de Lloyd foram os seguintes: 1) psicologia; 2) moral; 3) política. Na primeira parte do artigo, apresentarei esses aspectos inovadores em contraposição às interpretações tradicionais ou ortodoxas. Na segunda parte, confrontarei a abordagem de Lloyd com a abordagem tradicional sobre um problema específico, mas central na filosofia de Hobbes: o problema da desordem social. Em primeiro lugar, apresentarei a tese tradicional segundo a qual a solução para o problema da desordem seria criar um poder capaz de impor sanções que não permitissem que o interesse racional egoísta atuasse de forma irrestrita. Em segundo lugar, apresentarei a solução revisionista segundo a qual a solução seria produzir uma estável e apropriada reconfiguração dos diversos interesses morais e religiosos dos cidadãos através de um processo de educação contínua responsável pelo consenso social.

\section{Psicologia}

De acordo com a interpretação revisionista de Lloyd, o entendimento da psicologia humana atribuído a Hobbes pelos intérpretes tradicionais precisa ser reformulado nos seguintes termos: 1) ao invés de razão instrumental; razão recíproca; 2) ao invés de autointeresse; interesses morais e religiosos diversos.

De acordo com a abordagem de Lloyd, além da racionalidade instrumental, a compreensão de Hobbes da razão requer justificativas que atendam ao que ela denominou de "condição de reciprocidade". Segundo Lloyd (2009: 219-220), Hobbes elaborou uma espécie de "teorema da reciprocidade" que, em linhas gerais, funciona da seguinte maneira: a) o ser humano é um ser racional; b) na medida em que ele é racional, logicamente, suas ações não são contrárias à razão; c) aquilo que não é contrário à razão é julgado como 
racional. Entretanto, o que é julgado sem direito não é julgado como racional, portanto, qualquer julgamento feito sem direito é contrário à razão; d) assim, fazer o que se julga sem direito é agir contra a razão; e) se alguém julgar que o outro está fazendo uma ação sem direito, julga-se que a ação feita deve ser feita sem direito; f) portanto, se alguém julga que o outro está fazendo uma ação sem direito está agindo contra a razão. Isto é, fazer o que se condena em outro é contrário à razão.

Isso significa dizer que, para Lloyd, nenhuma ação que não se enquadre no teorema da reciprocidade, especialmente a cláusula (f), está de acordo com a razão, independente de que o objetivo de que faz determinada ação seja sua própria preservação ou benefício. Nesse sentido, as ações de um egoísta racional não devem ser consideradas racionais. Uma ação racional não é aquela que se concentra nos seus próprios fins, mas a que requer que as considerações que um determinado agente oferece aos outros como justificativas de suas próprias ações sejam considerações que alguém esteja disposto a aceitar de maneira recíproca.

As conclusões de Lloyd sobre a racionalidade como algo que depende de uma condição de reciprocidade (em contraposição à razão instrumental da interpretação tradicional) são derivadas da condição dos seres humanos em um hipotético estado de natureza, como descrito por Hobbes nos capítulos XIII do Leviatã. A concepção de racionalidade que permite uma condição de reciprocidade visa evitar a condição de mera natureza que ocorre quando cada indivíduo busca os seus próprios interesses, bem como alcançar o objetivo maior de qualquer ser humano em uma República: a paz.

Sobre os interesses morais diversos, segundo Lloyd, se toda a ação é autointeressada e se o único interesse racional é a autopreservação, como explicar a rebelião e mesmo a disposição de morrer por determinadas causas e ideais claramente não autointeressados? Por exemplo, como explicar que alguns súditos preferiam morrer por seus ideais morais e religiosos do que se submeter à autoridade absoluta do soberano? A resposta de Lloyd a essa questão é que todas as pessoas são capazes de agir motivadas por interesses morais e transcendentes tais como: liberdade, igualdade, dignidade humana ou a verdadeira religião (LLOYD, 1992: 1). Assim, entender o lugar dos interesses morais e transcendentes na interpretação de Lloyd é fundamental para entender sua tese de que Hobbes precisou prover razões para indivíduos que não eram guiados primordialmente pelo autointeresse.

Segundo Lloyd (Ibid., 1992; 51-52), Hobbes reconhece que as pessoas são motivadas por quatro tipos de interesses: (1) o interesse prudencial em sua sobrevivência física e em viver uma vida cômoda; (2) o interesse em cumprir seus deveres naturais e suas obrigações morais; (3) o interesse religioso em cumprir os seus deveres para com Deus; (4) o interesse em alcançar a salvação (o que Lloyd chama de "prudência especial"). Os últimos três interesses podem ser chamados de transcendentes, e possuem prioridade sobre o autointeresse na preservação física, tendo em vista que em nome desses interesses alguém poderá sacrificar sua própria vida a fim de que eles sejam realizados.

O interesse (1) está ligado à racionalidade em uma condição de reciprocidade. O argumento pode ser resumido da seguinte maneira: cada pessoa interessada na sua própria segurança e em uma vida cômoda possui uma razão estritamente prudencial para desejar que os outros venham a aderir ao princípio de Hobbes. O princípio a que Lloyd se refere aqui é o princípio de obrigação política, segundo o qual todo cidadão de uma República possui o dever de obedecer ao soberano em todas as suas ordens, com exceção de alguma ordem que conflite com o dever de obedecer a Deus. Assim, se alguém almeja que outros venham a aderir a esse princípio, então esse alguém possui um dever natural de aderir ele mesmo a esse princípio (LLOYD, 1992: 93). Em outras palavras, se nos reservarmos ao direito de não aderir ao princípio de Hobbes, devemos estar dispostos a aceitar que outros tenham o mesmo direito. De Acordo com Hobbes, "se [...] alguém exigir para si aquilo que não aceita que seja concedido aos outros, estará agindo contrariamente à lei 
precedente, que ordena o reconhecimento da igualdade natural, e contrariamente também, portanto, à lei de natureza" (HOBBES, 2014: 133).

O interesse (2) possui uma relação direta com o que Hobbes denominou de leis de natureza. Hobbes definiu uma lei de natureza (Lex Naturalis) como "um preceito ou regra geral, estabelecido pela razão, mediante o qual se proíbe a um homem fazer tudo que possa destruir a sua vida ou priva-lo dos meios necessários para a preservar" (Ibid., 112). Segundo Lloyd, os intérpretes ortodoxos supõem que Hobbes considera as leis da natureza como preceitos normativos por sua relação instrumental com a autopreservação. No entanto, em Morality in the Philosophy of Thomas Hobbes, Lloyd procura fornecer uma alternativa à interpretação ortodoxa das leis de natureza, demonstrando como essas leis sustentam sua interpretação de que os interesses morais e transcendentes na filosofia de Hobbes são a verdadeira motivação para que os cidadãos cumprissem as leis de natureza, bem como se mantivessem fieis aos pactos que haviam se submetido anteriormente.

Lloyd observa que a compreensão tradicional das leis de natureza de Hobbes está equivocada, na medida em que, condiciona a normatividade ao desejo primordial do agente pela autopreservação (LLOYD, 2009: 153). De acordo com sua interpretação, esse mal-entendido reverbera em toda a interpretação ortodoxa, sendo responsável pela atribuição aos seres humanos de uma racionalidade que não pode acomodar outros interesses além do autointeresse. (LLOYD, 2009: xiv-xv).

Os interesses ( 3 e 4) apresentam o que Lloyd denomina de "fase final do argumento compositivo de Hobbes”(LLOYD, 1992: 98), ou seja, um argumento capaz de fornecer motivações àqueles que possuem interesses que vão além do interesse na autopreservação e em uma vida cômoda, isto é, mesmo para os que possuem interesses religiosos que acreditam que entre obedecer a Deus e ao soberano, precisam manter o seu dever para com Deus (Ibid., 1992; 100).

De acordo com Hobbes, o dever de obedecer a Deus pode ser resumido nas duas crenças fundamentais do cristianismo sem as quais o individuo não pode ser salvo: a fé no Cristo e a obediência às leis (HOBBES, 2014: 490). No Leviatã, Hobbes seleciona as passagens bíblicas que ensinam que devemos nos submeter às autoridades para demonstrar racionalmente como a obediência ao soberano é um dever para com Deus:

Se a ordem do soberano civil for tal que possa ser obedecida sem a perda da vida eterna, é injusto não lhe obedecer, tendo lugar o preceito do Apóstolo: Servos, obedecei a vossos senhores em tudo e crianças, obedecei a vossos pais em todas as coisas (Ef 6.1-5); e o preceito do nosso Salvador: Os escribas e fariseus sentam-se na cadeira de Moisés, portanto observem e façam tudo o que eles disserem. (Mt 23.2-3) Mas se a ordem for tal que não possa ser obedecida sem que se seja condenado à morte eterna, então será loucura obedecer-lhe, e então tem lugar o conselho do nosso Salvador (Mt 10,28): Não temais aqueles que matam o corpo, mas não podem matar a alma. Portanto, todos os homens que quiserem evitar, quer as penas que lhes devem ser infligidas neste mundo pela desobediência ao seu soberano terreno, quer as que lhes serão infligidas no mundo que está para vir por desobediência a Deus, precisam de aprender a distinguir bem aquilo que é e aquilo que não é necessário para a salvação eterna (Ibid.)

Em resumo, o argumento de Hobbes é que a obediência à autoridade política só deve ser negligenciada caso haja, por parte do soberano, uma exigência que esteja claramente contra aquelas crenças absolutamente necessárias para que alguém alcance a salvação. Assim, ao fazer referência à fonte de autoridade dos cristãos, o objetivo de Hobbes é transformar a obediência às leis do soberano em um dogma equiparado ao dogma da fé no Messias.

Sobre o interesse na salvação (4), ele pode ser resumido da seguinte maneira: o desejo de obedecer 
à lei de Deus é uma exigência para a salvação. A lei de Deus por sua parte ordena a obediência à autoridade política existente. Assim, a intenção e o esforço para obedecer ao soberano se torna um requerimento para a salvação de alguém. Portanto, qualquer um que possui um interesse transcendente na sua própria salvação vai, de igual modo, possuir também um interesse transcendente em obedecer à autoridade civil. (HOBBES, 2014: 154).

Em suma, toda intepretação do Leviatã feita por Lloyd depende dessa redefinição da racionalidade e dos interesses na filosofia de Hobbes. A racionalidade humana não pode ser reduzida a racionalidade com respeito a fins. Nem tão pouco o cálculo racional visando a autopreservação é o interesse básico que motiva alguém a se submeter ao governo. Assim, para a interpretação revisionista de Lloyd, não existe um interesse racional responsável pela interação dos agentes entre si, algo que seja capaz de motivar esses agentes a obedecer ao soberano. O que existe é um conjunto de interesses: prudenciais, morais e religiosos, capazes de motivar as ações dos cidadãos uns para com os outros e dos cidadãos com a autoridade política.

\section{Moral}

A abordagem de Lloyd sobre a teoria moral de Hobbes se distingue da interpretação moral apresentada na tese Taylor-Warrender e da interpretação ortodoxa de David Gauthier. Isso significa dizer que, para Lloyd, a obrigação moral em Hobbes não acontece porque a lei de Deus nos obriga a agir moralmente, nem tão pouco deve ser atribuída à Hobbes a alcunha de subjetivista ou relativista moral.

Lloyd argumenta que Hobbes tem muito pouco a dizer sobre o status das declarações morais ou sobre as condições para o estabelecimento da verdade nesse campo. Segundo ela, Hobbes discute os significados dos termos morais caso a caso, definindo alguns termos como "justo", mas nunca oferecendo uma descrição teórica geral da retidão ou da bondade. (LLOYD, 1992: 266). No entanto, Hobbes estava longe de ser alguém que desconsiderava os efeitos e motivações morais presentes em determinadas ações dos seres humanos. A prova disso é o modo como tratou as suas leis de natureza.

O aspecto revisionista na abordagem de Lloyd sobre a filosofia moral de Hobbes consiste em redefinir o entendimento do papel das leis de natureza. (LLOYD, 2009: xiv). Em outras palavras, a interpretação revisionista de Lloyd se apresenta como uma alternativa à compreensão de que as leis de natureza não passam de advertências que devem ser acolhidas prudencialmente ou como leis literais legisladas por um Deus soberano. Segundo Lloyd, as leis de natureza devem ser entendidas como deveres naturais de cada homem para com os outros. (LLOYD, 2017: 203).

Os deveres naturais se referem à obrigação que temos de tratar os outros como a nós mesmos, bem como de tratar o soberano com a honra que lhe é devida. No entanto, segundo Lloyd, o entendimento das leis de natureza como deveres naturais não depende das palavras que Hobbes usa, mas do conteúdo dos conceitos que ele emprega. Para Lloyd, existe uma diferença entre obrigação e dever natural. Obrigações são compromissos voluntários, estabelecidos por contratos ou pactos. Em outras palavras, uma obrigação é uma espécie de promessa. Alguém promete fazer ou pagar algo (especificado pelo contrato) em troca de alguma consideração. Desse modo, as obrigações seriam contratuais ou uma questão de acordo mútuo.

Os deveres são diferentes. (LLOYD, 2013: 124). O que distingue um dever natural de uma obrigação é que o dever natural é capaz de fazer uma reivindicação sobre uma pessoa independentemente de seus compromissos voluntários. Isso significa dizer que um dever natural é, antes de tudo, um dever moral. De acordo com Lloyd, o teste que separa os conceitos de obrigação e dever natural é se a expressão: "eu nunca prometi isso" conta como uma defesa legítima para uma agressão moral. Segundo ela, se isso é capaz de 
defender um acusado de uma transgressão moral, então a violação em questão não pode ser de um dever natural, mas sim de uma obrigação. (LLOYD, 2017: 203). Outro exemplo seria se alguém afirmasse: "eu nunca prometi ter um relacionamento monogâmico" e isso servisse como defesa contra uma acusação de infidelidade, então, a monogamia não seria um dever natural, mas uma mera obrigação contratual. Por outro lado, se alguém afirmasse: "eu nunca prometi não torturar e matar pessoas inocentes por diversão", a violação seria de um dever natural. Assim, para Lloyd, os deveres naturais nos responsabilizam, quer queiramos ou não. (LLOYD, 2013: 125).

Lloyd observa que Hobbes afirma no Leviatã que as leis da natureza são "eternas e imutáveis", e o mais alto soberano é limitado por elas tanto quanto o mais humilde súdito: "os príncipes se sucedem uns aos outros; e um juiz passa e outro vem; mas, o céu e a terra passarão; mas nem um til da lei de natureza passará; porque ela é a eterna lei de Deus”. (HOBBES, 2014: 233). A lei natural não conhece fronteiras nacionais nem é regulada pela religião revelada. A característica fundamental que distingue um dever natural de uma obrigação contratual é a sua aplicabilidade universal. Isso significa dizer que, trata-se de uma lei moral. Contudo, resta-nos perguntar se a reinvindicação de Lloyd de que os deveres naturais têm aplicabilidade universal não faria da sua abordagem uma versão da tese Taylor-Warrender, na medida em que o mandamento de Deus fundamenta a natureza obrigatória e universal das leis de natureza.

Lloyd sustenta que Hobbes consistentemente apresenta as leis de natureza (que ele equaciona com "a verdadeira filosofia moral"), articulando-as às exigências de Deus para todos os que não desfrutam do benefício de uma revelação direta do próprio Deus. Assim, diferentemente da religião revelada, que é fonte de discórdia e agitação, as leis de natureza poderiam ser descobertas pelo mero exercício da razão natural, permitindo que não haja dúvida da sua reivindicação para a obediência de todos. (LLOYD, 2009: 4). Para Lloyd, o ponto de partida da filosofia moral de Hobbes é a nossa concepção compartilhada de nós mesmos como agentes racionais. Ela observa que a partir de nossa definição comum do ser humano como um ser racional, Hobbes argumenta que não devemos contar uma pessoa como racional, a menos que ela possa formular e esteja disposta a oferecer (pelo menos post-hoc) o que ele considera como justificativas racionais para sua conduta (e crenças). (LLOYD, 2010; 184).

Ao tentar conferir a aprovação de Deus às conclusões racionais da filosofia moral, Hobbes procura consolidar o apoio normativo aos princípios de estabilidade social presentes em sua filosofia política. Segundo Lloyd, a filosofia política completa a tarefa de reconciliação entre razão e religião, demonstrando que a Escritura, corretamente interpretada, confirma as conclusões da filosofia moral de Hobbes. ${ }^{1}$ É desse modo que sem vincular as leis de natureza diretamente a obrigações morais absolutas (semelhante ao que ocorre no imperativo categórico kantiano), nem tão pouco atribuir ao mandamento divino sua validade universal, Lloyd elabora um argumento normativo que redefine o papel e o entendimento das leis de natureza na filosofia moral de Hobbes.

Outro aspecto inovador da abordagem de Lloyd é sua tese de que a noção central da teoria moral de Hobbes é a reciprocidade, ao invés do autointeresse. Lloyd faz referência às palavras de Hobbes no Leviatã: "esta a lei do Evangelho: Faz aos outros o que queres que te façam a ti. E esta é a lei de todos os homens". (HOBBES, 2014: 113). De acordo com o teorema da reciprocidade de Lloyd, a razão exige que optemos, de maneira justa e racional, pela submissão conjunta ao julgamento de um árbitro público. Em outras palavras, se em uma República não há diferença entre os cidadãos, e se meu julgamento e capacidade não é melhor do que o de alguém, a razão exige que nós dois nos submetamos a algum mecanismo artificial de decisão

\footnotetext{
${ }^{1}$ Morality, p. 6.
} 
para resolver nossas disputas. Na teoria de Hobbes esse mecanismo artificial é o soberano. Assim, com base nesse princípio, Lloyd afirma que Hobbes fundamenta o dever natural de obedecer as suas leis de natureza.

\section{Política}

Para Lloyd, o problema político central do Leviatã é o problema da estabilidade e da desordem social causado pelos interesses transcendentes morais e religiosos. (LLOYD, 1992: 2). Lloyd entende que a teoria política de Hobbes é uma teoria da mente sobre a matéria. Isso significa dizer que Hobbes analisa o problema da desordem como resultado da primazia dos interesses morais e religiosos sobre os interesses materiais (o que inclui o interesse na autopreservação).

A interpretação baseada no autointeresse defende que em condições de escassez de recursos e de igualdade de poder, bem como na ausência de qualquer poder coercitivo que atue como árbitro das disputas, as atividades racionais dos indivíduos totalmente egoístas levarão necessariamente à desordem social. (Ibid., 25). No entanto, se essa interpretação estiver correta, então a solução seria criar um poder capaz de impor sanções que não permitissem que o interesse racional egoísta atuasse de forma irrestrita.

Para Lloyd, a solução proposta pela interpretação ortodoxa se dirige apenas a parte do problema, ou seja, essa solução estabeleceria a ordem e extinguiria momentaneamente a anarquia. Contudo, segundo ela, o projeto de Hobbes visa não apenas ao estabelecimento da ordem, mas à manutenção permanente dela. Assim, caso aceitemos a solução para o problema da desordem apresentada nos termos da interpretação ortodoxa, ainda precisamos apresentar uma solução para o problema da desordem recorrente que, segundo Lloyd, estava entre os objetivos de Hobbes ao escrever o Leviatã:

Muito tempo depois que os homens começaram a constituir Repúblicas, imperfeitas e susceptíveis de cair em desordem, podem ser descobertos, por meio de uma industriosa meditação, princípios racionais para tornar duradoura a sua constituição (excetuada a violência externa). E tais são aqueles que tenho apresentado neste discurso. (HOBBES, 2014: 285).

Segundo Lloyd, os princípios racionais capazes de tornar duradoura uma República são extraídos do próprio conceito de República (commonwealth) do modo como Hobbes o define. Esse conceito inclui determinadas funções de uma República, bem como os meios necessários para levar a cabo suas funções. Uma vez identificadas essas regras da razão, elas podem ser condensadas em um único princípio prescritivo dirigido a todos os cidadãos, um princípio de obrigação política que, se seguido, garantirá a perpetuação da estabilidade política (LLOYD, 1992: 58).

Hobbes define uma República como:

Uma pessoa de cujos atos uma grande multidão, mediante pactos recíprocos uns com os outros, oi instituída por todos como autora, de modo que ela pode usar a força e os recursos de todos, da maneira que considerar conveniente, para assegurar a paz e a defesa comuns. (HOBBES, 2014: 148).

Há sete elementos nessa definição que, segundo Lloyd, produzirão as várias regras da razão para a construção de uma República indestrutível e que juntas serão transformadas no único princípio de obrigação política de Hobbes. São eles 1) uma pessoa; 2) autorizada através de pactos mútuos; 3) por uma grande multidão; 4) para usar sua força; 5) seus meios; 6) como considerar conveniente; 7) para assegurar a paz e defesa comum. (LLOYD, 1993: 60). 
De acordo com Hobbes, a razão pela qual as pessoas se sujeitam a viver em uma República, permitindo que a sua liberdade seja coagida e renunciando ao seu direito natural a todas as coisas, reside no fato de que o seu desígnio ou interesse está na sua própria conservação e numa vida mais satisfeita. (HOBBES, 2014: 143). Isso corresponde à cláusula de número 7 da definição hobbesiana de República. Segundo Lloyd, se um dos objetivos dos cidadãos, quando se submetem à República, é a proteção, então uma das funções da República é providenciar tal proteção. Entretanto, para que a República providencie proteção para os seus membros contra os ataques dos inimigos, ela precisa ser razoavelmente grande (cláusula 3), de tal modo que nenhuma potência estrangeira possa confiar que poderá derrotá-la em uma guerra.

A fim de que seja possível assegurar a proteção e preservação dos seus membros contra o ataque dos estrangeiros, Hobbes argumenta que tal grupo precisa ser representado por uma única pessoa (cláusula 1) que também deve deter o poder de julgar qualquer questão relacionada à República. Isso se faz necessário porque as opiniões particulares dos que compõem a República tendem a divergir quanto a qual seria a melhor solução para proteger os cidadãos, prejudicando assim a função de proteger e de preservar que pertence à República. (HOBBES, 2014: 144-145).

Lloyd observa que a necessidade de a República ser dirigida por uma única pessoa possui profundas implicações para a teoria política de Hobbes. A razão pela qual uma República precisa ser dirigida por uma única pessoa é que se fosse dirigida por um monarca e um parlamento, ou por um monarca e a igreja, ou por um monarca e uma multidão, isso comprometeria a capacidade da República de proteger os seus membros pelo fato de existirem frequentes discordâncias entre os julgamentos privados. Assim, um único julgamento (cláusula 6) está de acordo com a regra da razão cujo objetivo é proteger os membros da República e assegurar a paz. Ser dirigido por tal pessoa significa seguir os seus julgamentos e decisões naquilo que ela acha que é necessário fazer. Isso inclui o emprego da força (cláusula 4) e os meios pelos quais isso é feito (cláusula 5). A cláusula final (2) pela qual uma República indestrutível pode ser formada é que ela precisa ser autorizada através de pactos mútuos. (HOBBES, 2014: 147).

Diante das cláusulas apresentadas na definição hobbesiana de uma República, Lloyd afirma que as várias regras da razão são reunidas em um único princípio registrado por Hobbes no Leviatã: “que os súditos devem aos soberanos simples obediência em todas as coisas nas quais a sua obediência não é incompatível com as leis de Deus" (Ibid., 299). Lloyd reformula esse princípio nos seguintes termos: "alguém deve obediência à autoridade política da República da qual é membro em todas as suas ordens, com exceção de alguma ordem que exija que alguém viole o seu dever para com Deus”. (LLOY, 1992: 69).

Esse princípio será apresentado com o objetivo de que os interesses primários das pessoas (interesses prudenciais) descritos por Hobbes nas partes II e III do Leviatã, sejam satisfeitos, fazendo com que a tarefa de Hobbes de prover razões suficientes para que haja adesão ao seu princípio seja bem-sucedida.

Entretanto, o único problema com o princípio de Hobbes é a sua cláusula de exceção: "com exceção de alguma ordem que exija que alguém viole o seu dever para com Deus”. Segundo Lloyd, mesmo a cláusula de exceção de Hobbes está estritamente ligada à função da República de proteger os seus membros. Isso significa que em circunstâncias em que a República não puder proteger os cidadãos, estes estão desobrigados de lhe obedecer. Embora muitas Repúblicas sejam eficazes na proteção dos seus membros, Lloyd observa que há uma coisa que nenhuma República pode fazer: "proteger o povo da ira de Deus". (LLOYD, 1992: 74). A razão disso é que nenhum soberano é tão poderoso quanto Deus. Portanto, se algum soberano ordenar algo que provoque a ira de Deus, os cidadãos não estão obrigados a obedecer a essas ordens, pelo simples fato de que o soberano não poderá protegê-los da ira de Deus. Por essa razão Hobbes escreve que "é perfeitamente evidente que, quando alguém recebe duas ordens contrárias e sabe que uma vem de Deus, tem 
de obedecer a esta e não à outra, embora seja a ordem do seu legítimo soberano”. (HOBBES, 2014: 489). Assim, a exceção de desobedecer ao soberano, se este se opuser ao dever para com Deus, pode, no entanto, ser motivo de discordância entre os cidadãos, principalmente sobre o que essa exceção exatamente permite e sobre o que a expressão “dever para com Deus” significa. Essa é uma dificuldade que o próprio Hobbes anteviu:

A dificuldade consiste, portanto, em que os homens, quando recebem ordens em nome de Deus, não sabem em alguns casos se a ordem vem de Deus, ou se aquele que ordena o faz abusando do nome de Deus para algum fim próprio e particular. Pois, assim como havia na Igreja dos judeus muitos falsos profetas que buscavam reputação junto do povo com visões e sonhos inventados, também tem havido em todos os tempos na Igreja de Cristo falsos mestres que procuram fama junto do povo com doutrinas fantásticas e falsas, e que por meio dessa reputação (tal como está na natureza da ambição) procuram governa-lo em benefício próprio. (HOBBES, 2014: 490).

Por essa razão, Hobbes deve especificar o que significa “o dever para com Deus", a fim de demonstrar que essa exceção não pode produzir uma desobediência que rompa com a ordem social.

Lloyd denomina de "redescrição dos interesses religiosos" a análise crítica de Hobbes das fontes do conhecimento religioso. O objetivo de Hobbes aqui é redefinir conceitos importantes para os grupos que se opunham à obediência ao soberano em todas as questões. Hobbes inicia o seu projeto de redescrição nos capítulos XXXI até XLIII do Leviatã. Ele identifica e redefine as seguintes fontes do conhecimento religioso: 1) a razão natural; 2) a revelação pessoal; 3) a profecia. É através da redefinição dessas três fontes do conhecimento religioso que é possível descobrir racionalmente o que é o dever para com Deus. (LLOYD, 1992: 113).

Hobbes inicia o processo de redefinição apresentando a razão natural como uma espécie de aferidor das demais fontes do conhecimento religioso. No capítulo XXXI do Leviatã ele afirma "que os súditos devem aos soberanos simples obediência em todas as coisas nas quais a sua obediência não é incompatível com as leis de Deus". (LLOYD, 2014: 299). Segundo Lloyd, Hobbes pretende demonstrar que nenhum dos nossos deveres para com Deus conflita com a razão natural nem com o fato de obedecermos à autoridade política, mesmo quando as suas ordens se dirigirem à esfera religiosa. Por exemplo, não existe apoio na razão natural para preferirmos alguma outra prática religiosa em detrimento daquela que a autoridade política ordena que observemos, e desde que a autoridade política é o representante da República, somente ele pode determinar a forma de adoração pública. Logicamente, esse era um argumento contra intuitivo, sobretudo, para as seitas protestantes independentes que defendiam que o único árbitro das questões religiosas deveria ser a Escritura cristã; não o soberano.

O segundo alvo de Hobbes são as revelações pessoais. De acordo com Hobbes, essa experiência é inacessível para as demais pessoas de uma República, sendo assim, a veracidade ou não de tal experiência dependerá da sinceridade de quem a relata e da crença de quem a ouve. (HOBBES, 2014: 314-315). Seu argumento se dirige aos autointitulados profetas, que pregavam a desobediência civil e que diziam terem ouvido do próprio Deus que o soberano não deveria ser obedecido. Em contra partida, para Hobbes, um alegado profeta que prega contra a República e a religião oficial precisa autenticar suas declarações com milagres ou alguma profecia cumprida. Lloyd observa que Hobbes sabia muito bem que os milagres cessaram desde os tempos dos apóstolos, e que o que precisamos para descobrir o que é o nosso dever para com Deus está na razão natural e nas Escrituras. Assim, seu argumento pode ser resumido da seguinte maneira: como não há milagres, não existem novos profetas para serem reconhecidos nem consultados sobre qual é 
o nosso dever para com Deus. Portanto, só saberemos qual é o nosso dever para com Deus consultando a nossa razão natural e as Escrituras. (LLOYD, 1992: 124).

A última fonte do conhecimento religioso redefinida em termos racionais por Hobbes é a profecia. Embora Hobbes já tenha questionado de modo implícito a profecia no capítulo XXXI, quando relativizou as revelações pessoais, Hobbes precisa apresentar um argumento específico contra as profecias, tendo em vista que a maior resistência em aderir aos seus princípios de obrigação política provinha delas. O objetivo de Hobbes na parte III do Leviatã é demonstrar que uma República cristã, embora governada por princípios sobrenaturais e pela vontade de Deus revelada na sua palavra escrita, não podia, sob hipótese alguma, contradizer os ditames da razão natural. Assim, qualquer discurso que alegadamente fosse uma profecia contra a autoridade da República deveria ser rejeitado como falso. (HOBBES, 2014: 366). Hobbes assevera que a verdadeira profecia está de acordo com a palavra escrita de Deus, logo, não pode contradizer a razão que afirma que é nosso dever para com Deus nos submeter ao soberano como legítimo "profeta de Deus", cuja missão é livrar a República do "caos primitivo, da violência e da guerra civil”. (Ibid.).

Assim, segundo a interpretação de Lloyd, para que haja adesão ao princípio de obrigação política de Hobbes, de que obedecer ao governo da República do qual alguém é membro não é algo repugnante diante do dever de obedecer a Deus, é necessário que os cidadãos sejam convencidos de seus equívocos. Isso faz com que a solução para o problema da desordem recorrente causada pelos interesses morais e religiosos conflitantes seja menos coercitiva do que a solução proposta pela interpretação ortodoxa. A solução para o problema da desordem, segundo a perspectiva revisionista consiste em produzir continuamente uma estável e apropriada reconfiguração dos interesses morais e religiosos das pessoas por um processo de educação contínua que gere o consenso.

\section{A razão pública como solução para o problema da desordem social}

Nesta seção, procurarei apresentar o resultado desses pressupostos aplicados a uma questão específica e central na filosofia de Hobbes: como resolver o problema da desordem social? Seguindo Hobbes, tanto a interpretação ortodoxa quanto a revisionista possuem uma resposta e uma solução para essa questão: o estabelecimento de uma "razão pública".

O conceito de razão pública possui uma vasta gama de significados e aplicações na filosofia política contemporânea. Uma definição consensual seria que a razão pública exige que as regras morais ou políticas que regulam nossa vida comum sejam, em certo sentido, justificáveis ou aceitáveis para todas as pessoas sobre as quais essas regras pretendem ter autoridade. Assim, o papel da razão pública nas democracias contemporâneas seria servir como um mecanismo de justificação entre as pessoas que razoavelmente discordam sobre questões filosóficas, religiosas e morais.

Entretanto, na filosofia hobbesiana, a razão pública é a razão de Estado que deve ser imposta (independe da aceitação de todas as pessoas) a fim de preservar a unidade da República. No Leviatã, o soberano representante da República recebe o nome de razão pública e a incumbência de agir como árbitro das disputas públicas. (HOBBES, 2014: 374). Como observa Gaus:

Hobbes procura, assim, demonstrar que o que o soberano proclama é razão pública. Nenhum limite pode ser colocado na autoridade do soberano: 'ele é o juiz do que é necessário para a paz; e juiz das doutrinas: ele é o único legislador; e juiz supremo das controvérsias’. (GAUS, 2015: 216). 
Aqui existe um consenso entre a interpretação ortodoxa e a revisionista, a saber, que a ideia de unificação da vontade na forma de um soberano absoluto é um pressuposto comum a ambas as interpretações. Nesse sentido, é consensual entre os intérpretes da filosofia de Hobbes que a sua solução para o problema da desordem é absolutista.

Assim, em primeiro lugar, apresentarei a tese ortodoxa segundo a qual a solução para o problema da desordem seria criar um poder capaz de impor sanções que não permitissem que o interesse racional egoísta atuasse de forma irrestrita.

Em segundo lugar, apresentarei a solução revisionista segundo a qual a solução seria produzir uma estável e apropriada reconfiguração dos diversos interesses morais e religiosos dos cidadãos através de um processo de educação contínua.

\section{A tese ortodoxa: a razão pública como o estabelecimento da ordem}

De acordo com essa tese, a resolução do problema da desordem acontece de modo muito simples: o argumento principal da interpretação ortodoxa promete proteção física e uma vida cômoda em troca de obediência quase irrestrita. (GAUTHIER, 1969: 18).

Em algumas passagens do Leviatã é possível corroborar com a tese ortodoxa do estabelecimento da ordem através de ameaças e punições por parte do Estado. Por exemplo:

É confiado ao soberano o direito de recompensar com riquezas e honras e o de punir, com castigos corporais ou pecuniários, ou com a ignomínia, qualquer súdito, de acordo com a lei que previamente estabeleceu. Caso não haja lei estabelecida, de acordo com o que considerar mais capaz de incentivar os homens a servir a república, ou de desestimular a prática de desserviços a ela. (HOBBES, 2014: 154).

E ainda:

Pertence à soberania ser juiz de quais as opiniões e doutrinas que são contrárias à paz, e quais as que lhe são propícias. E, em consequência, de em que ocasiões, até que ponto e o que se deve conceder àqueles que falam a multidões de pessoas, e de quem deve examinar as doutrinas de todos os livros antes de serem publicados. Pois as ações dos homens derivam das suas opiniões, e é no bom governo das opiniões que consiste o bom governo das ações dos homens, tendo em vista a paz e a concórdia entre eles. E embora em matéria de doutrina não se deva olhar para nada senão para a verdade, nada se opõe à sua regulação em função da paz. (HOBBES, 2014: 152).

No primeiro caso, pode ser demonstrado que o soberano por instituição pode, ocasionalmente, impor sanções e punir fisicamente os que ameaçarem a estabilidade da República. No segundo exemplo, as sanções são de outro tipo, elas se revestem de uma espécie de controle social cujo objetivo é controlar o discurso e o conteúdo dos livros que, porventura, fomentassem a desordem. Entretanto, a tese da necessidade de se estabelecer a ordem pela força do árbitro público, está pautada, sobretudo, nos pressupostos básicos da interpretação ortodoxa: 1) no mecanicismo que desemboca em uma concepção egoísta da psicologia humana; 2) na racionalidade instrumental, cujo único interesse é a autopreservação.

$\mathrm{Na}$ interpretação ortodoxa, o pressuposto de que os cidadãos são motivados pelo egoísmo psicológico é o responsável pelo conflito de interesses que resultará no benefício de um e no prejuízo do outro. É justamente isso que acontece no estado de natureza hobbesiano. A racionalidade instrumental, com a qual são guiados os seres humanos, faz com que a cooperação voluntária seja menos provável no estado de 
natureza pelo fato de que parece mais racional e vantajoso (dado o interesse básico que guia os seres humanos) evitar um acordo e obter uma vantagem unilateral, do que firmar um acordo de cooperação e obter vantagens menores.

Segundo essa interpretação, a racionalidade instrumental é tanto a fonte do problema da desordem social quanto a sua solução. Segundo Gauthier (1995: 27), a razão instrumental nos leva a elaborar os nossos próprios juízos privados, bem como a perseguir nossos próprios fins em detrimento de outros. Mas, se cada um exigir que sua própria razão seja tomada como certa, então a consequência será a guerra de todos contra todos. A solução para essa situação de conflito e medo permanente seria transferir o locus da deliberação individual para um árbitro ou razão pública a quem transferimos nosso direito natural. Assim, o mecanismo do contrato social entre os cidadãos cujo único interesse racional é autopreservação é, em suma, o grande responsável pela resolução do problema da desordem social na interpretação ortodoxa. Somente um árbitro pode, pela ameaça de sanções e pelo uso da força, fazer com que haja cooperação, obediência e ordem social.

\section{A tese revisionista: a razão pública como manutenção da ordem através da educação}

A solução revisionista para o problema da desordem social é um pouco mais complexa do que a proposta pela abordagem ortodoxa. Pode-se dizer também que ela é menos coercitiva do que a ortodoxa. Segundo Lloyd ((1992: 159), ela consiste em produzir continuamente uma estável e apropriada reconfiguração dos diversos interesses morais e religiosos dos cidadãos através de um processo de educação contínua capaz de gerar o consenso e a estabilidade social.

Contudo, assim como a tese ortodoxa, a viabilidade da tese revisionista dependerá de duas premissas: 1) A identificação dos fatores que geram a desordem social; 2) A defesa de que não apenas o estabelecimento da ordem, mas a sua manutenção é que resolverá o problema da desordem.

Sobre a primeira premissa, para a interpretação revisionista, as principais fontes da desordem são as opiniões privadas e os interesses morais e religiosos transcendentes. A abordagem revisionista se apoia em passagens que reforçam o poder desagregador dos interesses morais e religiosos:

O pretexto de sedição e de guerra civil mais frequente nas repúblicas cristãs teve durante muito tempo a sua origem numa dificuldade, ainda não suficientemente resolvida, de obedecer ao mesmo tempo a Deus e aos homens quando as suas ordens se contradizem. É perfeitamente evidente que, quando alguém recebe duas ordens contrárias e sabe que uma vem de Deus, tem de obedecer a esta e não à outra, emborra seja a ordem do seu legítimo soberano (quer se trate de um monarca quer se trate de uma assembleia soberana) ou a ordem do seu pai. (HOBBES, 2014: 489-490).

Para a abordagem revisionista, a interpretação ortodoxa apoiada no paradigma do egoísmo racional não precisa renunciar esse pressuposto: pode-se se sustentar que o interesse de alguém em obedecer a Deus reduz-se a um interesse em sua própria salvação. No entanto, se as pessoas estão pegando em armas, arriscando sua preservação pelo fato de acreditam que seu dever para com Deus está em jogo, como poderia a ameaça de punição física preservar a ordem social? Para Lloyd (1992: 38), esse problema é ainda mais agravado quando a salvação é trazida à cena, pois, quando confrontado com uma escolha entre a condenação eterna e punição temporal, o egoísmo racional certamente escolheria o último.

A segunda premissa entende que não se trata apenas de estabelecer a ordem através de ameaças e da violência, mas sim de manter a ordem perpetuamente, ou seja, de produzir a estabilidade da República. Essa premissa é importante porque é corroborada por uma passagem no Leviatã na qual Hobbes aponta para o 
problema da desordem recorrente:

Muito tempo depois que os homens começaram a constituir Repúblicas, imperfeitas e susceptíveis de cair em desordem, podem ser descobertos, por meio de uma industriosa meditação, princípios racionais para tornar duradoura a sua constituição (excetuada a violência externa). E tais são aqueles que tenho apresentado neste discurso. (HOBBES, 2014: 285).

O estabelecimento ordem, como propõe a leitura ortodoxa, seria apenas o primeiro estágio para a solução do problema da desordem. No entanto, esse estágio não garantiria a manutenção perpétua da República, a desordem poderia surgir e precisaria novamente ser reestabelecida em um círculo contínuo. Portanto, o problema para a leitura revisionista não é somente estabelecer, mas também manter a ordem social. A questão é: como realizar essa tarefa?

A resposta a essa questão consiste em implementar um processo continuo de educação visando a obediência e o cultivo de virtudes cívicas. Esse seria o segundo estágio para a solução hobbesiana do problema da desordem causada pelos interesses transcendentes morais e religiosos. Para a abordagem revisionista, a má compreensão desses interesses, principalmente dos interesses religiosos, eram a causa primária da guerra civil inglesa. Nesse sentido, um processo de reeducação seria responsável pela produção de interesses adequadamente concebidos, ou seja, os critérios da razão pública devem levar em consideração as razões para a aceitação do Estado.

O estabelecimento de um árbitro ou razão pública capaz de reconfigurar os interesses morais e religiosos transcendentes dos cidadãos através de um processo de educação constante torna-se fundamental para a tese revisionista. O soberano deve proteger os cidadãos integralmente. Isso inclui proteção física e intelectual. Por isso, Hobbes escreve:

Pertence à soberania ser juiz de quais as opiniões e doutrinas são contrárias à paz, e quais as que lhe são propícias. E, em consequência, de em que ocasiões, até que ponto e o que se deve conceder àqueles que falam a multidões de pessoas, e de quem deve examinar as doutrinas de todos os livros antes de serem publicados. Pois as ações dos homens derivam das suas opiniões, e é no bom governo das opiniões que consiste o bom governo das ações dos homens, tendo em vista a paz e a concórdia entre eles. E embora em matéria de doutrina não se deva olhar para nada senão para a verdade, nada se opõe à sua regulação em função da paz. (HOBBES, 2014: 152).

Para Hobbes, as universidades e as pregações nos púlpitos e nas ruas fomentavam a desordem social. Ele entende que o soberano, necessariamente, precisa controlar as opiniões, porque as ações dos homens derivam das suas opiniões, e é no bom governo das opiniões que consiste o bom governo das ações dos homens. Por essa razão, a manutenção da ordem faz com que seja necessária uma reforma nas universidades inglesas, sobretudo, pela forte influência de ideias cismáticas que ali eram veiculadas.

De acordo com essa visão, a ênfase de Hobbes na educação ou reeducação moral e política é fruto da sua compreensão de que a falta de educação era uma das principais causas da desordem social. Além disso, Hobbes acreditava que a reforma educacional seria a solução para a manutenção da ordem pelo fato de que, na República hobbesiana, as pessoas começam como uma "tábula rasa", mas uma vez que a educação formou suas opiniões, elas se tornam intratáveis, de tal modo que apenas através de muito esforço e de uma contínua e persistente reeducação é que se podem mudar suas opiniões. (LLOYD, 1992: 251). Isso significa dizer que a razão pública hobbesiana deve ser definida não como uma lei impositiva a qual os cidadãos se submetem pela coerção estatal, mas como um projeto educacional que visa transformar os cidadãos e a 
sociedade.

Como observa Mark Button (2008: 39), o conceito de razão pública em Hobbes inclui tanto a lei civil quanto a instrução pública, mas ambas as doutrinas não buscam apenas adesão exterior, mas o cultivo ético e político de um entendimento profundo da justiça além da observância dos pactos por razões prudenciais, da coerção e do medo. Segundo Button, ao criar essa solução Hobbes está demonstrando que não está satisfeito com os arranjos do contrato nem com a provisão de segurança pelo Estado meramente coercitivo.

Assim, a razão pública em Hobbes representa mais do que um poder coercitivo de direito público autorizado pelos cidadãos - ela representa as crenças, normas e virtudes que, com o tempo, vão formar todo o entendimento de cidadania em uma República. A questão para Hobbes é como formar e influenciar julgamentos privados. Isso significa dizer que a razão pública hobbesiana pode ser definida como um projeto transformativo.

\section{Considerações finais}

A interpretação revisionista de Lloyd trouxe à superfície questões negligenciadas pela interpretação ortodoxa ou tradicional da filosofia política e moral de Hobbes. A despeito das críticas que possam ser apresentadas à abordagem de Lloyd, sua contribuição é inegável. Sua concepção de racionalidade trouxe à luz uma psicologia mais complexa dos agentes hobbesianos, de maneira que interesses para além do interesse na autopreservação e da prudência estrita sejam reconhecidos. Essa compreensão inicial de que os indivíduos não são constituídos nem guiados por uma concepção instrumental da razão faz com que toda intepretação do Leviatã feita por Lloyd seja redefinida.

No entanto, a identificação dos pressupostos interpretativos de cada abordagem não diminui a complexidade da teoria contratualista de Hobbes e talvez nenhuma abordagem interpretativa seja capaz de fazer isso. Por exemplo, seja qual for o pressuposto do intérprete da filosofia moral e política de Hobbes, há uma conclusão consensual a respeito da sua solução: sua solução é absolutista. Talvez o absolutismo seja a melhor alternativa naquelas circunstâncias. Ainda mais se considerarmos que o objetivo de Hobbes não é apenas que uma República seja efetiva, mas que seja, sobretudo, estável.

Mesmo de acordo com a perspectiva revisionista segundo a qual o que mantém a República estável e unida é um processo de educação contínua, é necessário que haja a intervenção de um árbitro com poderes absolutos que seja responsável pelo controle da educação pública. Contudo, isso ainda não resolveria o problema da estabilidade da República, principalmente, se considerarmos a concepção pessimista que Hobbes tinha sobre a natureza humana e sua propensão para a rebelião e a desordem.

Assim como o problema do pluralismo moral parece insolúvel nas democracias modernas, o problema do pluralismo de interesses enfrentado por Hobbes parece intratável independente da perspectiva adotada. Entretanto, isso não significa dizer que as abordagens aqui apresentadas não foram capazes de articular soluções plausíveis. Mas, o fato de haver mais de uma abordagem acerca da solução hobbesiana para o problema da desordem social já revela a complexidade da questão.

\section{Referências}

BUTTON, Mark E. 2008. Where Justice is called a Virtue: public reason and civic formation in Thomas Hobbes. In. Contract, Culture, And Citzenship. Transformative Liberalism from Hobbes to 
Rawls. University Park, Pennsylvania: Pennsylvania State University Press.

GAUTHIER, David P. 1969. The Logic of Leviathan: the moral and political theory of Thomas Hobbes. Oxford: Oxford University Press.

1995. Public Reason. In. Social Philosophy and Policy Foundation, vol. 12 (n.1) pp. 19-42. DOI: $10.1017 /$ S0265052500004556.

GAUS, Gerald F. 2015. Public reason liberalism. In. WALL, Steven. (ed.). Cambridge Companion to Liberalism. Cambridge: Cambridge University Press.

LLOYD, S. A. 1992. Ideals as interests in Hobbe's Leviathan: the power of mind over matter. Cambridge: Cambridge University Press.

2009. Morality in the Philosophy of Thomas Hobbes: Cases in the Law of Nature. Cambridge: Cambridge University Press.

Bloomsbury companions.

2017. Duty without Obligation. Hobbes Studies. vol. 30, (n. 2) pp. 202-221. DOI: 10.1163/18750257-03002004

2010. The Moral Philosophy of Thomas Hobbes: A Reply to Critics. Hobbes Studies, vol. 23, (n. 2) pp. 180-187. DOI: 10.1163/187502510X531697

PETERS, Richard. 1956. Hobbes. Toronto, Ontario: Penguin Books.

RAWLS, John. 2012. Conferências sobre a História da filosofia política. São Paulo: Martins Fontes.

Artigo recebido em: 13 de janeiro de 2020

Artigo aceito em: 23 de fevereiro de 2019 